\title{
Intravascular papillary endothelial hyperplasia: Report of 4 cases with immu- nohistochemical findings
}

\author{
Marcia-Sampaio Campos, Roberto-A Garcia-Rejas, Décio-Santos Pinto Jr, Suzana-COM de Sousa, Fabio- \\ Daumas Nunes
}

Department of Oral Pathology, School of Dentistry, University of São Paulo, São Paulo, Brazil

Correspondence:

Av. Prof. Lineu Prestes, 2227, São Paulo, SP ZIP code 05508-000, Brazil

mscamp@usp.br

Received: $16 / 08 / 2008$ Accepted: $17 / 12 / 2008$

Campos MS, Garcia-Rejas RA, Pinto Jr DS, de Sousa SCOM, Nunes FD. Intravascular papillary endothelial hyperplasia: Report of 4 cases with immunohistochemical findings. Med Oral Patol Oral Cir Bucal. 2009 Oct 1;14 (10):e506-9.

http://www.medicinaoral.com/medoralfree01/v14i10/medoralv14i10p506.pdf

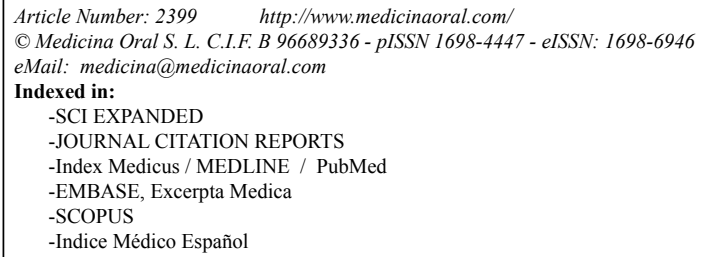

\begin{abstract}
Intravascular papillary endothelial hyperplasia (IPEH) is a benign endothelial proliferation, usually intravascular, that may mimic angiosarcoma. In this report, four new cases of IPEH involving the oral region are described. The affected sites were the lower lip, labial comissure and the submandibular region. After clinical evaluation, the complete removal of the lesions showed a circumscribed and soft mass. Histologically, the major feature was a reactive proliferation of endothelial cells composed of small papillary structures with hypocellular and hyalinized cores arising in an organized thrombus. Immunohistochemical staining for CD34 was strongly positive in endothelial cells. Vimentin and laminin immunolabelling were also consistent with a vascular origin. In order to verify the proliferative potential of the lesions, the $\mathrm{Ki}-67$ antibody was used, revealing low percentage of labeled cells $(<20 \%)$. No immunoreactivity for GLUT-1 was observed. Since the complete removal is curative, no additional treatment was necessary, and no signs of recurrence had been observed until now. Due to the particular features of IPEH, it is important for pathologists and clinicians to become familiar with this lesion. Additionally, the specific histological arrangement, including the absence of cellular pleomorphism, mitotic activity and necrosis, represents a guide to help in the differential diagnosis. Moreover, the vascular origin and the proliferative index should be assessed by immunohistochemistry in order to provide an accurate diagnosis.
\end{abstract}

Key words: Papillary endothelial hyperplasia, oral mucosa, immunohistochemistry. 


\section{Introduction}

Intravascular papillary endothelial hyperplasia (IPEH) is a relatively uncommon benign and non-neoplastic vascular lesion (1-4). It was first described by Masson in 1923, as an endothelial proliferation with associated thrombosis and fibrin deposition, leading to obliteration of the vascular lumen (1-4). It is histologically characterized by the presence of endothelium-lined papillary structures composed by a single layer of plump cells around a fibrin core that sometimes forms irregular anastomosing clefts, simulating an angiosarcoma (5-8). However, the absence of cellular pleomorphism, mitotic activity and necrosis represent a differential feature of IPEH (5). The prognosis of this lesion is excellent, and recurrence is an unusual finding. It is cured by simple excision in primary forms, and by treating the underlying condition in the secondary ones $(6,8)$. Its pathogenesis is usually associated with trauma, but recently it has been reported as an unusual form of organized thrombus (6-8).

In this article, four additional cases of oral IPEH are presented with immunohistochemical findings and a brief review of the literature. Additionally, clinical and histological aspects are also discussed.

\section{Case reports}

Clinical, histological and immunohistological findings. All four cases presented here were previously approved for this purpose, by the appropriate institutional review board (IRB). The clinical data of the cases are summarized in Table 1. Clinically, the lesions were asymptomatic and the affected sites included lower lip (2 cases), submandibular region (one case) and labial comissure (one case). The average patient age was 45 years (ranging from 28 to 72 years), and the treatment was the complete excision of the lesion. The cases date from 2000, 2004 and 2006, and no signs of recurrence have been reported until now. Additionally, in a total of 60.000 oral biopsies experienced in our diagnosis service, only these four IPEH were found among 1650 vascular lesions. Microscopically, sections of all cases revealed a pseudoencapsulated mass confined within a dilated vascular space, represented by papillary fronds lined by proliferating endothelium. Small collagenized structures surrounded by granulation tissue were observed (Fig. 1A). These structures were lined by a single layer of plump endothelium and showed hypocellular and hyalinized cores (Fig. 1B).

An associated thrombus was also seen, but no significant atypia, mitotic activity or necrosis were present. Immunohistochemical reactions for CD-34 and vimentin revealed strong positivity in the lining endothelial cells confirming the vascular origin of the lesion (Fig. 1C). Laminin and vimentin were also positively stained in the mesenchymal component (Fig. 1D,1E). Ki-67 antibody (Fig. 1F) labeled less than $20 \%$ of the cell component of the lesion and GLUT-1 was negative. These findings are in conformity with the diagnosis of the IPEH.

\section{Discussion}

Although vascular lesions are relatively common in the oral region, IPEH is an uncommon benign, non-neoplastic, vascular lesion (1-4), comprising approximately $2 \%$ of the benign and malignant vascular tumors of the skin and subcutaneous tissues (8). The differential diagnosis includes pyogenic granuloma, hemangioma and angiosarcoma $(2,3,5,8-10)$. However, angiosarcomas usually occur in different clinical settings and are extravascular with an infiltrative growth pattern that dissects through collagen bundles. Additionally, these lesions display moderate-to-marked cytologic atypia with prominent mitotic activity (2). The IPEH can be distinguished from other lesions due to its frequently

Table 1. Clinical findings of the 4 new oral IPEH cases

\begin{tabular}{|c|c|c|c|c|c|}
\hline \multicolumn{6}{|c|}{ Clinical findings } \\
\hline ID & Age & Gender & Site/size & $\begin{array}{c}\text { Clinical } \\
\text { diagnosis }\end{array}$ & $\begin{array}{c}\text { Evolution } \\
\text { time }\end{array}$ \\
\hline 1 & 48 years & Male & $\begin{array}{l}\text { Multilobulated, non-ulce- } \\
\text { rated purple-red mass in } \\
\text { Lower lip }(10 \times 10 \mathrm{~mm})\end{array}$ & Mucocele & 11 months \\
\hline 2 & 28 years & Female & $\begin{array}{l}\text { Nodule in Submandibular } \\
\text { region }(15 \times 10 \mathrm{~mm})\end{array}$ & Not informed & 5 months \\
\hline 3 & 32 years & Male & $\begin{array}{c}\text { Non-ulcerated, red- } \\
\text { dish soft mass in Lower } \\
\operatorname{lip}(10 \times 10 \mathrm{~mm})\end{array}$ & $\begin{array}{l}\text { Pleomorphic } \\
\text { adenoma }\end{array}$ & 4 months \\
\hline 4 & 72 years & Male & $\begin{array}{l}\text { Non-ulcerated, reddish } \\
\text { soft mass in Labial comis- } \\
\text { sure }(12 \times 7 \mathrm{~mm})\end{array}$ & $\begin{array}{l}\text { Pyogenic } \\
\text { granuloma }\end{array}$ & 1 year \\
\hline
\end{tabular}



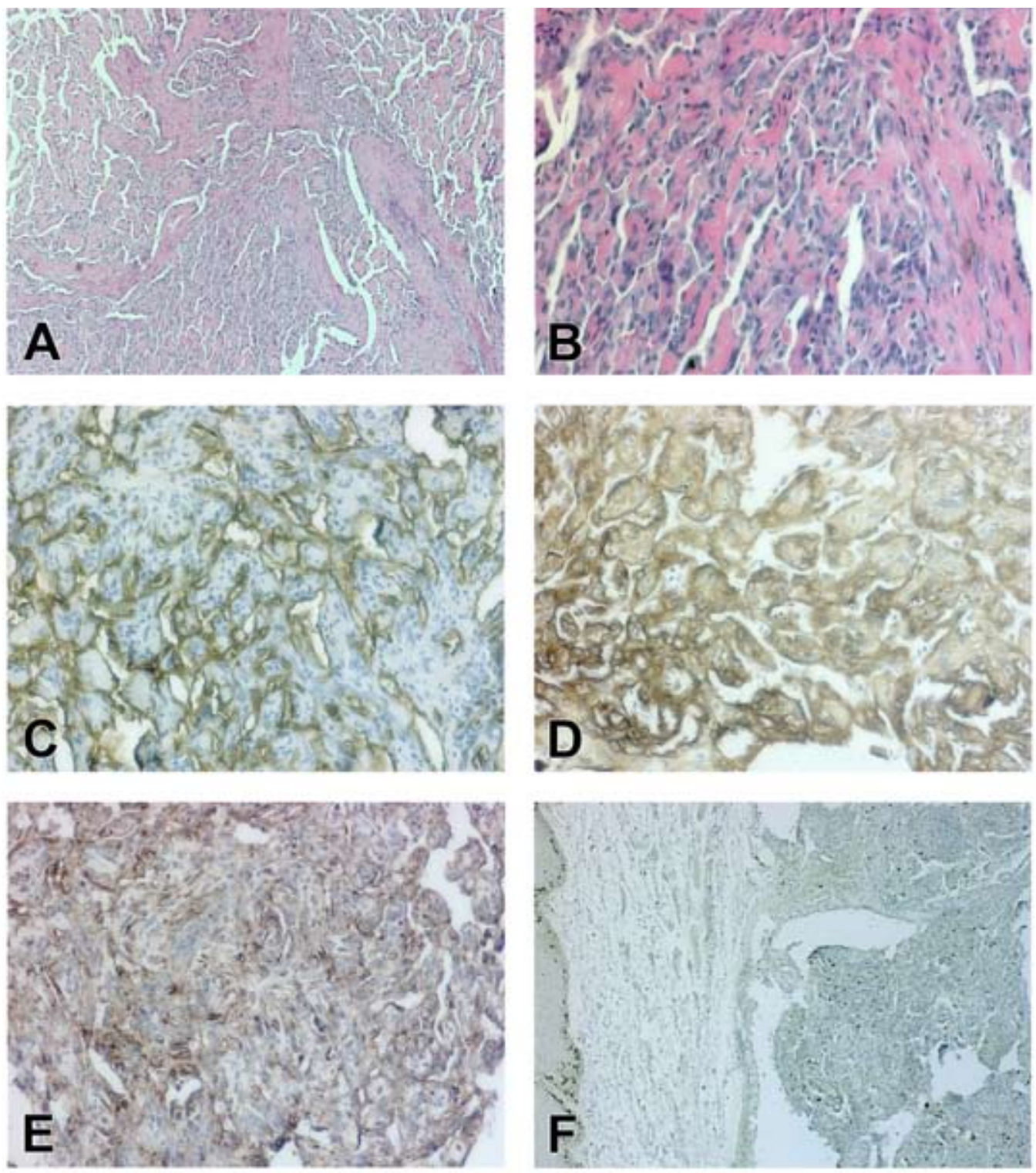

Fig. 1. Histopathologic and immunohistochemical aspects. A, Small collagenized structures surrounded by a fibrous stroma (original magnification 25X). B, Papillae structures lined by a single layer of plump endothelium and showing hypocellular and hyalinized cores (original magnification 100X); C, Strong immunopositivity for CD-34 in most of the endothelial cells (original magnification 100X). D, Immunopositivity for laminin in the endothelial cells inside the lesion (original magnification 100X). E, Immunopositivity for vimentin in the lining endothelial cells (original magnification 100X). F, Weak immunopositivity for Ki-67 in the endothelial cells.

well-circumscribed or encapsulated feature, with the proliferative process entirely limited by a vascular wall and characterized by papillary fronds. Moreover, IPEH is generally associated with a thrombus, which precedes the formation of the fronds and serves as a matrix for their development (10). The present cases were not completely encapsulated, but a thrombus was seen in all of them.

As observed in data provided here, the clinical hypothesis included pyogenic granuloma, pleomorphic adenoma and mucocele, but they did not include IPEH. It points out the importance of a better knowledge of this lesion among clinicians in order to include it in their differential diagnosis. Generally, the complete surgical excision is the best therapy for patients with IPEH, being both diagnostic and curative. Recurrence is unusual, being only reported when the excision is not complete (6) or when an underlying vascular lesion, such as an intramuscular hemangioma or pyogenic granuloma is associated to the lesion $(5,8)$. 
Clinically, IPEH presents as a tender firm mass and reddish-blue color to the overlying skin or mucous membrane, as observed in the four reported cases. The patients ages range from 9 months to 80 years, which was observed in the cases report here. On the other hand, the higher incidence in females as compared to males $(6,8)$ could not be seen in the 4 cases reported in this paper. According to the literature, approximately 80 cases of oral IPEH were described from 1976 to 2006, and they were slightly more frequent in the lower lip, followed by upper lip, tongue, buccal mucosa and mandibular vestibule $(1-4,7,10,11)$. In this report, it was found that two cases involved the lower lip, corroborating the literature data. The other two cases presented unusual affected sites (labial comissure and submandibular region), deserving particular attention.

Immunohistochemically, the vascular origin of the lesion was demonstrated by its positive reaction for CD34 and vimentin (2). In agreement to the literature $(2,10)$, vimentin reacted not only with the mesenchymal cells but also with endothelial cells, suggesting that the present lesions are in an early stage of development. On the other hand, Ki-67 positive cells were rarely seen in all of the four cases, indicating that the proliferating activity was low. GLUT-1, a protein constitutively found in the placenta, erythrocytes, and fetal membranes, has been suggested as a useful auxiliary marker for the diagnosis of the oral benign vascular lesions (12). The present results showed negative reaction to GLUT-1, in agreement to a previous study presented by Johann et al. (12).

Benign vascular tumors are very common and it is often difficult to determine whether they are malformations, true neoplasms or, in some cases, reactive processes. In the cases presented here, since the histological features suggested a vascular origin, the authors used the CD34 to confirm this hypothesis. Although it is known that CD34 is a good vascular marker, it is also accepted that vascular lesions are very difficult to distinguish using only immunohistochemistry. In general, CD31 and $\mathrm{CD} 34$ are the recommended markers for benign vascular lesions and, according to the histological features of each particular case, other markers can be used, such as muscle-specific actin (2). Particularly, the immunohistochemistry represents an important adjunctive procedure in the diagnosis of angiosarcomas (specially for poorly differentiated forms in which vascular channel formation is difficult to identify). As well as in benign vascular lesions, angiosarcomas express a greater or lesser degree of the usual vascular antigens, including von Willebrand factor, CD31 and CD34. Based on this, to assess if IPEH could be differentiated from malignant vascular tumors, the proper approach should be the analysis of histological aspects (e.g. mitosis, pleomorphism) $(2,6)$.
In conclusion, the present report was focused on the description of clinical, histological and immunohistochemical findings of the IPEH that might be helpful for clinicians. The authors also point to $\mathrm{Ki}-67$ as a good marker of the proliferative potential of these lesions, in order to predict possible recurrences or misdiagnosis. Moreover, it is important for oral pathologists and clinicians to be familiarized with this lesion since it is rare and can be misdiagnosed as an angiosarcoma. Awareness of this lesion will prevent incorrect diagnosis and avoid aggressive treatment.

\section{References}

1. De Courten A, Küffer R, Samson J, Lombardi T. Intravascular papillary endothelial hyperplasia of the mouth: report of six cases and literature review. Oral Dis. 1999;5:175-8.

2. Matsuzaka K, Koike Y, Yakushiji T, Shimono M, Inoue T. Intravascular papillary endothelial hyperplasia arising from the upper lip. Bull Tokyo Dent Coll. 2003;44:55-9.

3. Devi M, Nalin Kumar S, Ranganathan K, Saraswathi TR. Oral intra vascular papillary endothelial hyperplasia in the floor of the mouth. Indian J Dent Res. 2004;15:149-51.

4. Wang XY, Namiq A, Fan F. A 55-year-old woman with a buccal mass. Intravascular papillary endothelial hyperplasia. Arch Pathol Lab Med. 2006;130:877-8.

5. Inalöz HS, Patel G, Knight AG. Recurrent intravascular papillary endothelial hyperplasia developing from a pyogenic granuloma. J Eur Acad Dermatol Venereol. 2001;15:156-8.

6. Kim D, Israel H, Friedman M, Kuhel W, Langevin CJ, Plansky T. Intravascular papillary endothelial hyperplasia manifesting as a submandibular mass: an unusual presentation in an uncommon location. $\mathrm{J}$ Oral Maxillofac Surg. 2007;65:786-90.

7. Santonja C, De Sus J, Moragón M. Extramedullary hematopoiesis within endothelial papillary hyperplasia (Masson's pseudoangiosarcoma) of the tongue. Med Oral Patol Oral Cir Bucal. 2007;12:E556-9. 8. Anthony SG, Mudgal CS, DeLaney TF, Shin RD, Raskin KA, Ring DC. Recurrent intravascular papillary endothelial hyperplasia of the right middle finger treated with radiation therapy. J Bone Joint Surg Br. 2008;90:95-7.

9. Buchner A, Merrell PW, Carpenter WM, Leider AS. Oral intravascular papillary endothelial hyperplasia. J Oral Pathol Med. 1990;19:41922.

10. Tosios K, Koutlas IG, Papanicolaou SI. Intravascular papillary endothelial hyperplasia of the oral soft tissues: report of 18 cases and review of the literature. J Oral Maxillofac Surg. 1994;52:1263-8.

11. Tokman B, Simşek S, Erkmen E, Oygur T. Intravascular papillary endothelial hyperplasia of the mandibular lingual mucosa. Chin Med J (Engl). 2004;117:1756-7.

12. Johann AC, Salla JT, Gomez RS, De Aguiar MC, Gontijo B, Mesquita RA. GLUT-1 in oral benign vascular lesions. Oral Dis. 2007;13:51-5. 